\title{
Left Ventricular Diastolic Dysfunction Detected by Speckle Tracking in Hypertensive Patients with Preserved Ejection Fraction
}

\author{
Kamal Ahmed Marghany, Yasser Abd El Galeel Omar and Hosam Hussien Kamel Abdalghany* \\ Department of Cardiology, AL-Azhar University, Egypt
}

Submission: June 15, 2017; Published: July 03, 2017

*Corresponding author: Hosam Hussien Kamel Abdalghany, Department of Cardiology, AL-Azhar University, Cairo, Egypt,

Email: drhosamhussien@Hotmail.com

\begin{abstract}
Objectives: To detect early diastolic dysfunction in the left ventricle in hypertensive patients with preserved ejection fraction using 2D
\end{abstract} speckle tracking echocardiography.

Methods: This is a prospective study that was carried on (80) hypertensive patients referred to Al Azhar university hospital outpatient clinic for evaluation and treatment of hypertension and (20) age and sex matched healthy volunteers as a control group. All subjects underwent convential echocardiographic examination and assesment of diastolic dysfunction by speckle tracking.

Conclusion: Impairment of diastolic function detected by speckle tracking in hypertensive patients (with and without LVH).

Keywords: Hypertension; Speckle tracking; Echocardiography

\section{Introduction}

Hypertension is a well-recognized risk factor for cardiovascular disease and a major contributor to a large percentage of heart failure cases as a result of left ventricular (LV) systolic pressure overload due to an increase in peripheral vascular resistance which results in various LV geometric changes that progresses to diastolic heart failure and/or heart failure with LV systolic dysfunction [1]. Early detection of LV dysfunction before the development of LVH may represent a clinical finding that would necessitate aggressive treatment aimed at reducing cardiovascular morbidity and mortality; it has to be considered in the assessment of global cardiovascular risk [2]. Advances in echocardiography over the last decades have provided new methods of analysis particularly analysis of myocardial strain by speckle tracking which enables quantitative \& detailed assessment of $\mathrm{LV}$ function with high level of diagnostic accuracy [3]. This technique can be used to study myocardial strain in all its dimensions longitudinal, circumferential, transversal, radial and twist. Strain analysis may detect subclinical cardiac involvement in hypertensive and thus identify asymptomatic patients who may be at risk for adverse effects [4]

The Aim of the Study

To detect early diastolic dysfunction in the left ventricle in hypertensive patients with preserved ejection fraction using 2D speckle tracking echocardiography.

\section{Patients and Methods}

\section{Study design}

This is a prospective study that was carried from April 2015 to March 2017 on (80) hypertensive patients referred to $\mathrm{Al}$ Azhar University hospital outpatient clinic for evaluation and treatment of hypertension and (20) age and sex matched healthy volunteers as a control group. They were enrolled in the study after obtaining their written informed consent. Diagnosis of hypertension was based on ESH/ESC guidelines for management of hypertension if SBP $\geq 140 \mathrm{mmHg}$ and/or DBP $\geq 90 \mathrm{mmHg}$ on two or more hospital visits at one week interval [5]. 


\section{The study population was divided into three groups}

a. Group I (Control Group): Included 20 normotensive healthy age and sex matched volunteers free from cardiovascular risk factors.

b. Group II: Included 40 hypertensive patients without echocardiographic criteria of LVH.

c. Group III: Included 40 hypertensive patients with echocardiographic criteria of LVH.

d. Exclusion criteria: It included patients with ejection fraction $<50 \%$ or with symptoms or sign of heart failure, diabetes mellitus, patients with known coronary artery disease, patients with significant valvular disease and patients with atrial fibrillation or other rhythm disturbances.

\section{Methods}

The following data were collected:

a. Complete and detailed medical History: With attention to Hypertension, DM and family history of premature coronary artery disease.

b. Full clinical examination including body surface area [6], heart rate, rhythm, systolic, diastolic blood pressure, heart, and chest auscultation.

c. Conventional echocardiographic Doppler study and 2D speckle tracking were performed using Philips iE33 X Matrix ultrasound machine using X5-1 matrix array transducers (Philips Medical Systems, Andover, USA).

\section{Systolic function assessment}

a. Ejection fraction (EF\%) and fractional shortening (FS\%) were performed to evaluate LV systolic function By 2D echo.

b. LVEDV and LVESV were calculated from the apical 2-and 4-chamber views using a modified biplane Simpson's method.

c. Ejection fraction (EF\%) was calculated as percentage changes of volumes of the left ventricle in diastole and systole. The LV ejection fraction (EF\%) was automatically calculated as follows [7] :

$(\mathrm{EF} \%)=(\mathrm{EDV}-\mathrm{ESV}) / \mathrm{EDV} \times 100$

Diastolic function assessment: LV diastolic function was evaluated using pulsed wave doppler; Doppler studies were recorded from apical 4-chamber view, with a sample volume

Table 1: Comparison between three groups according to Age positioned within the inflow portion of the LV, midway between the annular margins of mitral valve.

4-Two-dimensional speckle tracking echocardiography (2D STE): Longitudinal strain rate was assessed in the $6 \mathrm{LV}$ walls and the software algorithm automatically segmented the $\mathrm{LV}$ into 18 equidistant segments and each segment was analyzed separately. The average value of peak early diastolic SR (SRe s-1), peak late diastolic SR (SRa s-1) at each segment (basal, mid and apical) and global LV diastolic SR obtained from averaging the peak values of $18 \mathrm{LV}$ segments were calculated and used for comparisons between control and hypertensive groups (Figure 1). All variables in this study represent the mean value of measurements taken in 3 consecutive cardiac cycles.

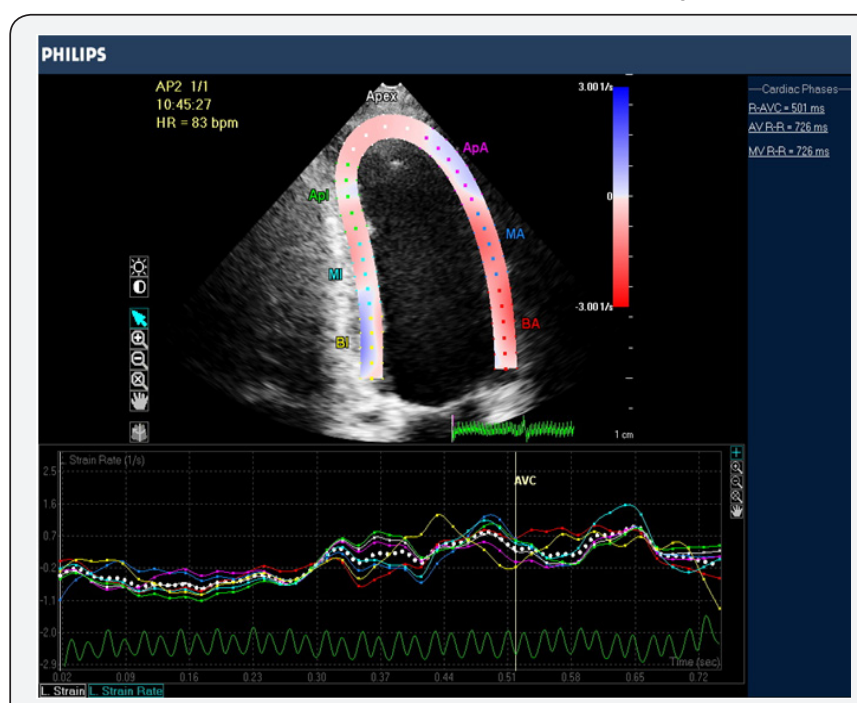

Figure 1: Apical 2 chamber view demonstrate diastolic strain rate in hypertensive patient without LVH.

Statistical analysis: Data were fed to the computer and analyzed using IBM SPSS software package version 20.0. (Armonk, NY: IBM Corp). The Kolmogorov-Smirnov test was used to verify the normality of distribution Quantitative data were described using range (minimum and maximum), mean, standard deviation and median. Significance of the obtained results was judged at the $5 \%$ level.

The used tests were F-test (ANOVA) for normally distributed quantitative variables to compare between more than two groups and Post Hoc test (Tukey) (LSD) for pair wise comparisons.

\section{Results}

Regarding Demographic and Clinical data: In the present study, there were no significant differences between the three groups as regards age and sex (Table $1 \& 2$ ).

\begin{tabular}{|c|c|c|c|c|c|c|c|c|}
\hline Data & $\begin{array}{c}\text { Group I } \\
\text { (Control) }\end{array}$ & $\begin{array}{c}\text { Group II (No } \\
\text { LVH) }\end{array}$ & $\begin{array}{c}\text { Group III } \\
\text { (with LVH) }\end{array}$ & \multicolumn{2}{|c|}{ Anova } & \multicolumn{2}{|c|}{ Tukey's test } \\
\hline Age(year) & Mean \pm SD & Mean \pm SD & Mean \pm SD & F & P-Value & P1 & P2 & P3 \\
\hline
\end{tabular}




\begin{tabular}{|l|c|c|c|c|c|c|c|c|}
\hline & $50.5 \pm 6.0$ & $51.6 \pm 5.1$ & $52.2 \pm 6.0$ & 6.138 & & 0.13 & 0.36 & 0.12 \\
\hline
\end{tabular}

P1=between group I \& II, P2=between group I \& III, P3=between group II \& III P value $>0.05=$ insignificant, P $<0.05=$ Significant, P $<0.001=$ highly significant.

Table 2: Comparison between three groups according to Gender

\begin{tabular}{|c|c|c|c|c|c|c|c|}
\hline \multicolumn{2}{|c|}{ Sex } & \multicolumn{3}{c|}{ Groups } & Chi-square \\
\cline { 3 - 8 } & & $\begin{array}{c}\text { Group I } \\
\text { (control) N=20 }\end{array}$ & $\begin{array}{c}\text { Group II (No } \\
\text { LVH) N =40 }\end{array}$ & $\begin{array}{c}\text { Group III } \\
\text { (With LVH) N } \\
\mathbf{5 4 0}\end{array}$ & Total N=100 & X $^{2}$ & P-Value \\
\hline Female & N (\%) & $12(60 \%)$ & $23(57.5 \%)$ & $25(62.5 \%)$ & $60(60 \%)$ & 1.515 & 0.469 \\
\hline Male & N (\%) & $8(40 \%)$ & $17(42.5 \%)$ & $15(37.5 \%)$ & $40(40 \%)$ & & \\
\hline
\end{tabular}

\section{Conventional echocardiography}

Left ventricular posterior wall thickness (PWd), LA dimensions, inter ventricular septal thickness (IVSd), left ventricular mass (LVM) were higher in hypertensive patients

with LVH (group III) than hypertensive patients without LVH (group II) and the control group (group I), while E/A ratio was lower in hypertensive patients (groups II and III) than in the control group (group I) (Table $3 \& 4$ ).

Table 3: Comparison between three groups according to Echocardiographic parameters.

\begin{tabular}{|c|c|c|c|c|c|c|c|c|}
\hline & \multirow{2}{*}{$\begin{array}{l}\text { Group I } \\
\text { (Control) }\end{array}$} & \multirow{2}{*}{$\begin{array}{l}\text { Group II (No } \\
\text { LVH) }(n=30)\end{array}$} & \multirow{2}{*}{$\begin{array}{c}\text { Group III } \\
\text { (with LVH) } \\
(n=30)\end{array}$} & \multicolumn{2}{|c|}{ ANOVA } & \multicolumn{2}{|c|}{ Tukey's test } & \multirow[b]{2}{*}{$\mathbf{p}_{3}$} \\
\hline & & & & $\mathbf{F}$ & $\mathbf{p}$ & $\mathbf{p}_{1}$ & $\mathbf{p}_{2}$ & \\
\hline FS (\%) & $3.33 \pm 36.30$ & $3.21 \pm 36.77$ & $3.50 \pm 38.00$ & 1.798 & 0.173 & 0.88 & 0.191 & 0.333 \\
\hline $\mathrm{EF}(\%)$ & $4.55 \pm 65.60$ & $3.94 \pm 66.47$ & $4.31 \pm 67.87$ & 1.845 & 0.165 & 0.759 & 0.159 & 0.411 \\
\hline PWD (cm) & $0.12 \pm 0.88$ & $0.15 \pm 0.93$ & $0.09 \pm 1.16$ & $39.201^{*}$ & $<0.001^{*}$ & 0.391 & $<0.001^{*}$ & $<0.001^{*}$ \\
\hline LVIDS (cm) & $0.34 \pm 3.01$ & $0.26 \pm 2.93$ & $0.44 \pm 3.10$ & 1.682 & 0.193 & 0.702 & 0.682 & 0.165 \\
\hline LVIDD $(\mathrm{cm})$ & $0.54 \pm 4.75$ & $0.73 \pm 4.48$ & $0.34 \pm 5.04$ & $7.489^{*}$ & $0.001^{*}$ & 0.228 & 0.176 & $0.001^{*}$ \\
\hline IVSD (cm) & $0.12 \pm 0.90$ & $0.37 \pm 1.02$ & $0.09 \pm 1.25$ & $14.081^{*}$ & $<0.001 *$ & 0.170 & $<0.001 *$ & $0.001^{*}$ \\
\hline LV mass & $30.70 \pm 143.70$ & $27.16 \pm 144.73$ & $26.19 \pm 238.07$ & $107.166^{*}$ & $<0.001 *$ & 0.991 & $<0.001 *$ & $<0.001^{*}$ \\
\hline $\mathrm{AO}(\mathrm{cm})$ & $0.28 \pm 2.95$ & $0.41 \pm 2.93$ & $0.34 \pm 3.12$ & 2.558 & 0.084 & 0.979 & 0.217 & 0.096 \\
\hline $\mathrm{LA}(\mathrm{cm})$ & $0.25 \pm 3.59$ & $0.42 \pm 3.73$ & $0.35 \pm 4.02$ & $10.049^{*}$ & $<0.001^{*}$ & 0.356 & $<0.001^{*}$ & $0.006^{*}$ \\
\hline
\end{tabular}

$\mathrm{P} 1=$ between group I \& II, P2=between group I \&III, P3=between group II \& III P value $>0.05=$ insignificant, $\mathrm{P}<0.05=$ significant, $\mathrm{P}<$ $0.001=$ highly significant.

Table 4: Comparison between the three studied groups according to mitral Doppler inflow.

\begin{tabular}{|c|c|c|c|c|c|c|c|c|}
\hline \multirow{2}{*}{$\begin{array}{c}\text { Mitral } \\
\text { Doppler } \\
\text { inflow }\end{array}$} & \multirow{2}{*}{$\begin{array}{l}\text { Group I } \\
\text { (Control) (n } \\
=20)\end{array}$} & \multirow{2}{*}{$\begin{array}{c}\text { Group II (No } \\
\text { LVH) }(\mathrm{n}= \\
30)\end{array}$} & \multirow{2}{*}{$\begin{array}{l}\text { Group III } \\
\text { (With LVH) } \\
(\mathrm{n}=30)\end{array}$} & \multicolumn{2}{|c|}{ ANOVA } & \multicolumn{3}{|c|}{ Tukey's test } \\
\hline & & & & $\mathbf{F}$ & $\mathbf{p}$ & p1 & p2 & p3 \\
\hline E/A ratio & $0.30 \pm 1.38$ & $0.36 \pm 0.88$ & $0.32 \pm 0.87$ & $16.815^{*}$ & $<0.001^{*}$ & $<0.001^{*}$ & $<0.001^{*}$ & 0.994 \\
\hline
\end{tabular}

p1=between group I \& II, p2=between group I \&III, p3=between group II \& III P value $>0.05=$ insignificant, $P<0.05=$ significant, $P$ $<0.001=$ highly significant. 


\section{Journal of Cardiology \& Cardiovascular Therapy}

\section{D-speckle tracking imaging}

There was a stepwise reduction in The global early diastolic strain rate (SRe s-1) from group I (control) to group II (HTN without LVH) to group III (HTN with LVH) (Table 5 and Figure
2). On the other hand, the global late diastolic strain rate (SRa s-1) was significantly increased in both group II (HTN without LVH) and group III (HTN with LVH) when compared to group I (control) as shown in (Table 6 and Figure 3).

Table 5: Comparison between the three studied groups according to cumulative early diastolic strain rate $\mathrm{E}$.

\begin{tabular}{|c|c|c|c|c|c|c|c|c|}
\hline & \multirow{2}{*}{$\begin{array}{c}\text { Group I } \\
(\text { Control) } \\
(\mathrm{n}=20)\end{array}$} & \multirow{2}{*}{$\begin{array}{c}\text { Group II } \\
\text { (No LVH) } \\
(\mathrm{n}=\mathbf{3 0})\end{array}$} & \multirow{2}{*}{$\begin{array}{l}\text { Group } \\
\text { III (With } \\
\text { LVH) (n = } \\
\text { 30) }\end{array}$} & ANOVA & & & $\begin{array}{c}\text { Tukey's } \\
\text { test }\end{array}$ & \\
\hline & & & & $\mathbf{F}$ & $\mathbf{p}$ & p1 & p2 & p3 \\
\hline \multicolumn{9}{|c|}{ Cumulative } \\
\hline Septal & $0.30 \pm 1.40$ & $0.36 \pm 1.28$ & $0.19 \pm 0.90$ & $21.536^{*}$ & $<0.001 *$ & 0.374 & $<0.001^{*}$ & $<0.001^{*}$ \\
\hline Lateral & $0.34 \pm 1.43$ & $0.37 \pm 1.25$ & $0.25 \pm 0.95$ & $14.635^{*}$ & $<0.001^{*}$ & 0.143 & $<0.001^{*}$ & $0.001^{*}$ \\
\hline Inferior & $0.23 \pm 1.48$ & $0.40 \pm 1.40$ & $0.27 \pm 0.85$ & 31.323* & $<0.001^{*}$ & 0.686 & $<0.001^{*}$ & $<0.001^{*}$ \\
\hline Anterior & $0.21 \pm 1.44$ & $0.40 \pm 1.32$ & $0.18 \pm 1.04$ & $13.067^{*}$ & $<0.001^{*}$ & 0.316 & $<0.001^{*}$ & $0.001^{*}$ \\
\hline Posterior & $0.31 \pm 1.47$ & $0.47 \pm 1.20$ & $0.23 \pm 1.09$ & $6.899^{*}$ & $0.002^{*}$ & $0.028^{*}$ & $0.001 *$ & 0.468 \\
\hline Antseptal & $0.37 \pm 1.46$ & $0.52 \pm 1.09$ & $0.28 \pm 1.02$ & $7.608^{*}$ & $0.001 *$ & $0.006^{*}$ & $0.001 *$ & 0.802 \\
\hline Global LV & $0.22 \pm 1.45$ & $0.30 \pm 1.26$ & $0.14 \pm 0.98$ & $27.083^{*}$ & $<0.001^{*}$ & $0.016^{*}$ & $<0.001^{*}$ & $<0.001^{*}$ \\
\hline
\end{tabular}

$\mathrm{p}_{1}=$ between group I \& II, p2=between group | \&III, p3=between group II \& III P value $>0.05=$ insignificant, $P<0.05=$ significant, $P$ $<0.001=$ highly significant

Table 6: Comparison of the study groups regarding cumulative LV Late diastolic Strain Rate (SRa s-1).

\begin{tabular}{|c|c|c|c|c|c|c|c|c|}
\hline & \multirow{2}{*}{$\begin{array}{c}\text { Group I } \\
\text { (Control) } \\
(n=20)\end{array}$} & \multirow{2}{*}{$\begin{array}{c}\text { Group II } \\
\text { (No LVH) } \\
(n=30)\end{array}$} & \multirow{2}{*}{$\begin{array}{l}\text { Group } \\
\text { III (With } \\
\text { LVH) (n = } \\
\text { 30) }\end{array}$} & \multicolumn{2}{|c|}{ ANOVA } & \multicolumn{3}{|c|}{ Tukey's test } \\
\hline & & & & $\mathbf{F}$ & $\mathbf{p}$ & $p_{1}$ & $\mathbf{p}_{2}$ & $\mathbf{p}_{3}$ \\
\hline \multicolumn{9}{|c|}{ Cumulative } \\
\hline Septal & $0.34 \pm 0.78$ & $0.18 \pm 0.94$ & $0.27 \pm 0.98$ & $3.957^{*}$ & $0.023^{*}$ & 0.077 & $0.022^{*}$ & 0.831 \\
\hline Lateral & $0.30 \pm 0.71$ & $0.19 \pm 0.82$ & $0.32 \pm 0.89$ & 2.844 & 0.064 & 0.315 & 0.049 & 0.559 \\
\hline Inferior & $0.15 \pm 0.77$ & $0.26 \pm 0.80$ & $0.27 \pm 1.11$ & $16.943^{*}$ & $<0.001^{*}$ & 0.924 & $<0.001^{*}$ & $<0.001^{*}$ \\
\hline Anterior & $0.17 \pm 0.69$ & $0.20 \pm 0.95$ & $0.33 \pm 0.99$ & 9.508* & $<0.001^{*}$ & $0.001^{*}$ & $<0.001^{*}$ & 0.859 \\
\hline Posterior & $0.37 \pm 0.72$ & $0.20 \pm 0.87$ & $0.28 \pm 1.03$ & $7.521 *$ & $0.001 *$ & 0.177 & $0.001^{*}$ & 0.066 \\
\hline Antseptal & $0.29 \pm 0.60$ & $0.28 \pm 0.92$ & $0.35 \pm 1.14$ & $18.012^{*}$ & $<0.001^{*}$ & $0.002^{*}$ & $<0.001^{*}$ & $0.022^{*}$ \\
\hline Global LV & $0.16 \pm 0.71$ & $0.17 \pm 0.88$ & $0.22 \pm 1.02$ & $16.754^{*}$ & $<0.001 *$ & $0.006^{*}$ & $<0.001^{*}$ & 0.013* \\
\hline
\end{tabular}

p1=between group I \& II, p2=between group | \&III, p3=between group II \& III P value $>0.05=$ insignificant, $P<0.05=$ significant $\mathrm{P}<0.001=$ highly significant.

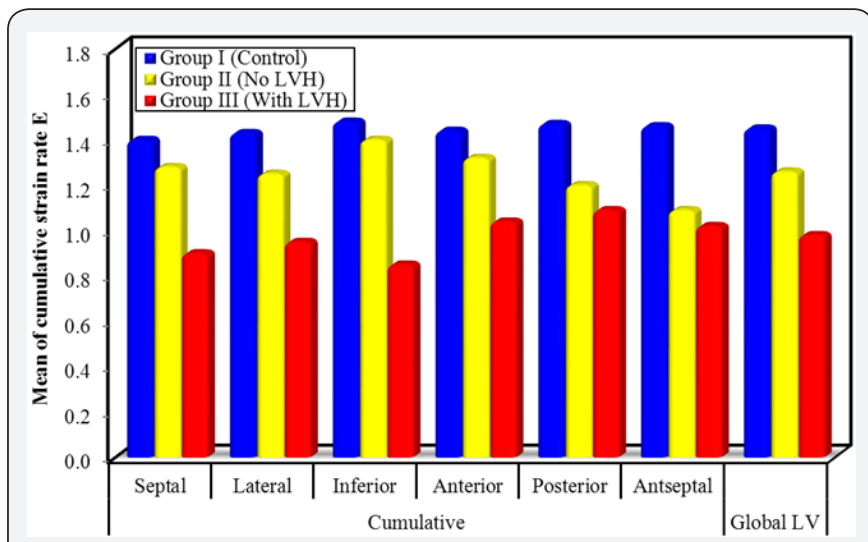

Figure 2: Comparison of the study groups regarding cumulative LV early diastolic strain rate.

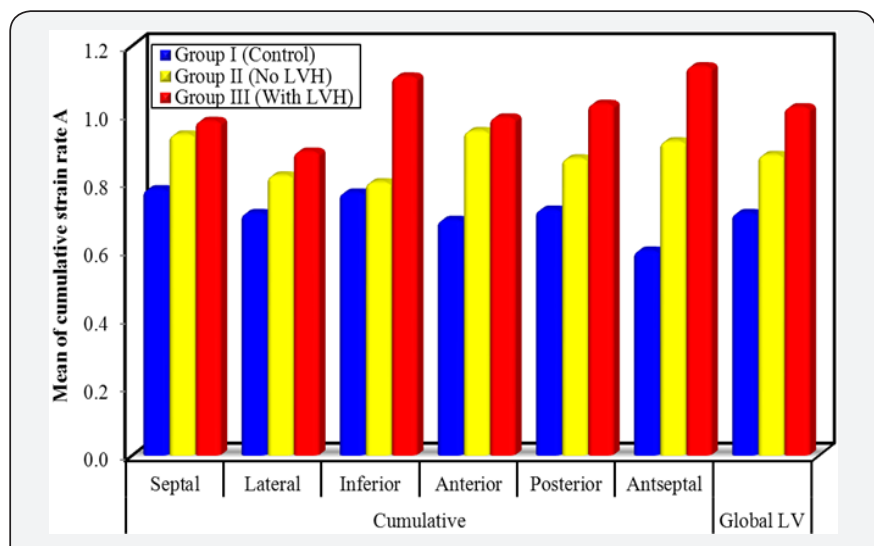

Figure 3: Comparison of the study groups regarding cumulative LV late diastolic strain rate. 


\section{Discussion}

Strain $(\varepsilon)$ is a measure of tissue deformation. As the ventricle contracts, muscle shortens in longitudinal and circumferential dimensions (a negative strain) and thickens or lengthens in radial direction (a positive strain). Strain rate (SR) is the local rate of deformation that measures the time course of deformation or strain per unit time [8].

In contrast to TDI, speckle tracking echocardiography is an angle-independent technique that allows an accurate assessment of segmental myocardial deformation by grey-scale based imaging analysis frame by frame. Moreover, the lack of angle-dependency is of great advantage as myocardial strain $(\varepsilon)$ could be tracked in two dimensional echo imaging along the direction of the wall and not along the ultrasound beam [9].

The present study was designed to evaluate LV diastolic functions in hypertensive patients using 2D-speckle tracking echocardiography based on longitudinal strain rate.

\section{Regarding LV diastolic function assessed by conventional pulsed wave doppler}

The findings of the present study demonstrated significant impairment of LV diastolic function in hypertensive patients when compared with control group, as shown by inversion of the E/A ratio, in hypertensive patients with and without LVH. The high prevalence of diastolic impairment among hypertensive patients may be attributed to LV thickening and the ultimate myocardial fibrosis with progression of the disease.

This was explained by Cuocolo et al. [10], who demonstrated that, $\mathrm{LV}$ relaxation is impaired in subjects with $\mathrm{LVH}$ arising from chronic pressure overload owing to increased myocardial mass and resultant increase in interstitial connective tissue leading to increased LV stiffness. This goes in harmony with the findings of Zabalgoitia [11], who investigated 665 hypertensive patients; $62 \%$ of them had $\mathrm{LVH}$, by conventional echocardiography to evaluate mitral flow patterns and its relationship to LV systolic and diastolic functions and found that the inversion of the E/A ratio was the most prevalent pattern (79\%).

This was also supported by M. Dekleva et al. [12], who studied 30 hypertensive patients and demonstrated that all patients had preserved systolic function but impaired LV relaxation. This was further explained by López et al. [13], who stated that, serological evidence of myocardial fibrosis in hypertensive heart disease (HHD) was demonstrated by experimental and clinical data and directly linked to abnormalities in diastolic function and myocardial stiffness.

\section{Regarding LV diastolic function assessed by diastolic strain rate}

The present study showed that the strain rate value was significantly reduced in both hypertensive patients with and without LVH in early diastole (at peak E) and in late diastole (at peak A) in comparison to control group. This goes with the results of $\mathrm{Mu}$ et al. [14], who studied 75 hypertensive patients with normal left ventricular geometry and 50 healthy persons and found that; early diastolic strain rate value, late diastolic strain rate value of $\mathrm{LV}$ longitudinal strain rate were reduced in hypertensive patients compared with normal group.

This was in agreement with Goebel et al. [15], who found that, there is decrease in peak longitudinal systolic strain rate $\&$ also decrease in longitudinal early diastolic strain rate in hypertensive patients when compared to normal subjects. In addition, systolic twist rate and diastolic untwist rate were significantly lower in this patient group. They concluded that, LVH in hypertensive patients mainly affect longitudinal and circumferential deformation rate.

Huang Chun Yan studied 88 patients with essential hypertension in comparison to 30 normotensive age and gender matched healthy volunteers served as controls. His Analysis showed that there is impairment of longitudinal early diastolic strain rate in hypertensive patients in comparison with control group. Hence, it was concluded that, speckle tracking imaging may be helpful for early detection of subclinical changes in LV diastolic function in patients with hypertension.

\section{References}

1. Cameli M, Lisi M, Righini FM, Massoni A, et al. (2013) Left ventricular remodeling and torsion dynamics in hypertensive patients. Int J Cardiovasc Imaging 29(1): 79-86.

2. Conen D, Pfisterer M, Martina B (2006) Substantial intraindividual variability of BNP concentrations in patients with hypertension. J Hum Hypertens 20(6): 387-391.

3. Van Dalen BM, Soliman OI, Vletter WB, Kaue F, Zwaan HB, et al. (2009) Feasibility and reproducibility of left ventricular rotation parameters measured by speckle tracking echocardiography. Eur J Echocardiogr 10(5): 669-676.

4. Geyer H, Caracciolo G, Abe H, Wilansky S, Carerj S, et al. (2010) Assessment of myocardial mechanicsusing speckle tracking echocardiography fundamentals and clinical applications. J Am Soc Echocardiogr 23(4): 23351-23369.

5. Mancia G, Fagard R, Narkiewicz K, Redo' n J, Zanchetti A, et al. (2013) ESH/ESC guidelines for the management of arterial hypertension. The task force for the management of arterial hypertension of the European Society of Hypertension (ESH) and of the European Society of Cardiology (ESC). J Hypertens 31(7): 1281-1357.

6. DuBois D, DuBois EF (1989) A formula to estimate the approximate surface area if height and weight be known. 1916. Nutrition 5(5): 303311.

7. Simpson IA (1997) Echocardiographic assessment of long axis function a Simple solution to a complex problem? Heart 78(3): 211-212.

8. Weidemann F, Jamal F, Sutherland GR, Claus P, Kowalski M, et al. (2002) Myocardialfunction defined by strain rate and strain during alterations in inotropic states and heart rate. Am J Physiol Heart Circ Physiol; 283(2): 792-799.

9. Dandel M, Lehmkuhl H, Knosalla C, Suramelashvili N, Hetzer R (2009) Strain and Strain Rate Imaging by Echocardiography-Basic Concepts and Clinical Applicability. Curr Cardiol Rev 5(2): 133-148. 
10. Cuocolo A, Sax FL, Brus JE, Maron BJ, Bacharach SL et al. (1990) Left ventricular hypertrophy and impaired diastolic filling in essential hypertension. Diastolic mechanisms for systolic dysfunction during exercise. Circulation 81(3): 978-986.

11. Zabalgoitia M (1996) Left ventricular mass and function in primary hypertension. Am J Hypertens 9(8): 55s-59s.

12. Dekleva M, Pencic B, Bakic-Celic V, Kostic N, Ilic S, et al. (2003) Impact of left ventricular diastolic dysfunction on maximalexercise capacity in hypertensive patients. Eur J Echocardiography (03): 791-798.

13. López B, Querejeta R, González A, Sánchez E, Larman M, et al. (2004) Effects of loop diuretics on myocardial fibrosis and collagen type Iturnover in chronic heart failure. J Am Coll Cardiol 43(11): 2028-2035.
14. Mu Y, Qin C, Wang C, Huojiaabudula G (2010) Two-dimensional ultrasound speckle tracking imaging in evaluation of early changes in left ventricular diastolic function in patients with essential hypertension. Echocardiography 27(2): 146-154.

15. Goebel B, Gjesdal O, Kottke D, Otto S, Jung C, et al. (2011) Detection of irregular patterns of myocardial contraction in patients with hypertensive heart disease: a two-dimensional ultrasound speckle tracking study. J Hypertens 29(11): 2255-2264.

\section{Your next submission with Juniper Publishers will reach you the below assets}

- Quality Editorial service

- Swift Peer Review

- Reprints availability

- E-prints Service

- Manuscript Podcast for convenient understanding

- Global attainment for your research

- Manuscript accessibility in different formats ( Pdf, E-pub, Full Text, Audio)

- Unceasing customer service

Track the below URL for one-step submission https://juniperpublishers.com/online-submission.php 